\title{
Synthesis of Some Isocoumarin Derivatives
}

\author{
By Jwei-l'au Lin, Shigeo Yoshida and Nobutaka Takahashi \\ Department of Agricultural Chemistry, The University \\ of Tokyo, Tokyo, Japan \\ Received September 13, 1971
}

Piericidins $\mathrm{A}$ and $\mathrm{B}$, natural insecticides, have been isolated from mycellia of Streptomyces mobaraensis. ${ }^{1,21}$ Later, some other metabolites such as piericidin X, A-, B- and Xsubstance have been isolated from the same fungus, and A- and B-substance identified ${ }^{3 \prime}$ as 3-methyl-6, 7-dimethoxy-8-hydroxyisocoumarin
(Ia) and 3-methyl-7-methoxy-6,8-dihydroxyisocoumarin (reticulol, $\mathrm{Ib}$ ), respectively. This paper describes the synthesis of A-substance (Ia), as well as the preparation of some 3alkoxyisocoumarins.

3-( $3^{\prime}, 4^{\prime}, 5^{\prime}$-Trimethoxyphenyl)-propionic acid (II) was prepared from gallic acid by the

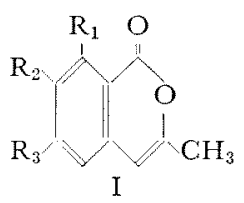

a $\mathrm{R}_{1}=\mathrm{OH}, \mathrm{R}_{2}=\mathrm{R}_{3} \ldots \mathrm{OCH}_{3}$

b $\mathrm{R}_{1}=\mathrm{R}_{3}=\mathrm{OH}, \mathrm{R}_{2}=\mathrm{OCH}_{3}$

c $\mathrm{R}_{1}=\mathrm{R}_{2}=\mathrm{R}_{3}=\mathrm{OCH}_{3}$

d $\mathrm{R}_{1}=\mathrm{R}_{3}=\mathrm{OCH}_{3}, \mathrm{R}_{2}=\mathrm{H}$

e $\mathrm{R}_{1}=\mathrm{OH}, \mathrm{R}_{2}=\mathrm{H}, \mathrm{R}_{3}=\mathrm{OCH}_{3}$

f $\mathrm{R}_{1}=\mathrm{R}_{2}=\mathrm{R}_{3}=\mathrm{H}$
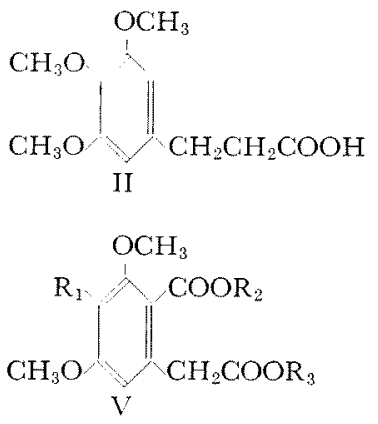

a $\mathrm{R}_{1}=\mathrm{OCH}_{3}, \mathrm{R}_{2}=\mathrm{R}_{3}=\mathrm{H}$

b $\mathrm{R}_{1}=\mathrm{OCH}_{3}, \mathrm{R}_{2}=\mathrm{H}, \mathrm{R}_{3}=\mathrm{Et}$

c $\mathrm{R}_{1}=\mathrm{R}_{2}=\mathrm{H}, \mathrm{R}_{3}=\mathrm{Et}$

d $\mathrm{R}_{1}=\mathrm{R}_{3}=\mathrm{H}, \mathrm{R}_{2}=\mathrm{CH}_{3}$
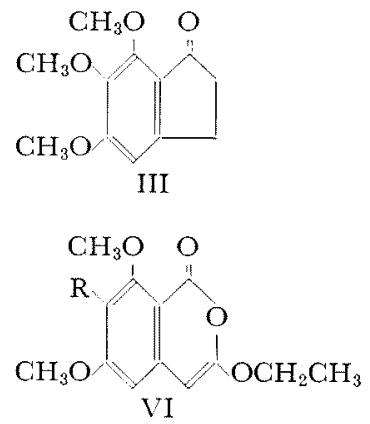

a $\mathrm{R}=\mathrm{OCH}_{3}$

b $\mathrm{R}=\mathrm{H}$
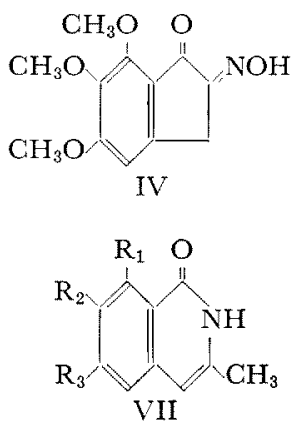

a $\quad \mathrm{R}_{1}=\mathrm{OH}, \mathrm{R}_{2}=\mathrm{R}_{3}=\mathrm{OCH}_{3}$

c $\mathrm{R}_{1}=\mathrm{R}_{2}=\mathrm{R}_{3}=\mathrm{OCH}_{3}$

d $\mathrm{R}_{1}=\mathrm{R}_{3}=\mathrm{OCH}_{3}, \mathrm{R}_{2}=\mathrm{H}$

e $\mathrm{R}_{1}=\mathrm{OH}, \mathrm{R}_{2}=\mathrm{H}, \mathrm{R}_{3}=\mathrm{OCH}_{3}$

f $\mathrm{R}_{1}=\mathrm{R}_{2}=\mathrm{R}_{3}=\mathrm{H}$ 
method of $\mathrm{Koo}^{51}$ with some modifications. * II was converted to 5,6,7-trimethoxy-1-indanone (III) by heating with polyphosphoric acid. According to the method applied to the synthesis of mellein by Matsui et al. ${ }^{6}$ III was treated with isoamyl nitrite to give 5,6,7-trimethoxy-2-oximino-1-indanone (IV), $\mathrm{mp}$ 189 $190^{\circ} \mathrm{C}$, which was converted to 2-carboxy-3,4, 5-trimethoxyphenylacetic acid ( $\mathrm{Va}), \mathrm{mp} 151^{\circ} \mathrm{C}$ by the Beckmann rearrangement followed by alkali hydrolysis, and then $\mathrm{Va}$ was refluxed in acetic anhydride for $2 \mathrm{hr}$ to give 3-methyl6,7,8-trimethoxyisocoumarin (Ic). A milder reaction condition than that used by Matsui et al. is enough for the conversion of $\mathrm{Va}$ to Ic. This reaction condition could be used for the synthesis of 3-methylisocoumarin (If) and 3-methyl-6,8-dimethoxyisocoumarin (Id) ${ }^{7}$ from the corresponding homophthalic acid derivatives. Hydrolysis of Ic with hydriodic acid yielded 3-methyl-6,7-dimethoxy-8-hydroxyisocoumarin (Ia). This was identical with A-substance isolated from Streptomyces mobaraensis in all respects, melting point, IR, NMR and mass spectra. The over-all yield of Ia from II was $53 \%$.

In the course of this synthesis, we found that a half ester of $\mathrm{Va}(\mathrm{Vb})$ was converted to 3-ethoxy-6,7,8-trimethoxyisocoumarin ( $\mathrm{VIa}$ ) by refluxing in acetic anhydride. By this method 3-ethoxy-6,8-dimethoxyisocoumarin (VIb) was also prepared.

On heating with $28 \%$ ammonia in seeled tube at $100^{\circ} \mathrm{C}, 3$-methylisocoumarin derivatives (Ia, c, d, e, f) were transformed into the corresponding 1-hydroxyisoquinoline derivatives (VIIa, c, d, e, f) in good yield.

\section{EXPERIMENTAL}

All melting points were uncorrected. IR spectra

\footnotetext{
* In the process of the preparation of II, reduc-

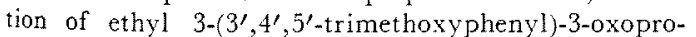
pionate with paladium charcoal was unsuccessful in our hand. We used the Clemmensen reduction in this conversion.
}

were determined with a JASCO IRS-KCl spectrophotometer in nujol mulls for solid samples. NMR spectra were run with JNM-4H 100 spectrometer in $\mathrm{CDCl}_{3}$ unless otherwise stated and chemical shifts are expressed in - value. Mass spectra were obtained by RMU-6L equipped with a direct inlet system: electron accelerating voltage, $70 \mathrm{eV}$; chamber temperature, $200 \sim 310^{\circ} \mathrm{C}$.

3-( $3^{\prime}, 4^{\prime}, 5^{\prime}$-Trimethoxyphenyl $)$-propionic acid $(I I)$. To the solution of ethyl $3-\left(3^{\prime}, 4^{\prime}, 5^{\prime}\right.$-trimethoxyphenyl)-3oxopropionate $(10 \mathrm{~g})$ in toluene $(100 \mathrm{ml})$ were added amalgamated zinc $(3 \mathrm{~g})$ and $21 \%$ hydrochloric acid $(70 \mathrm{ml})$ and the reaction mixture was refluxed for 48 hr and then extracted with ethyl acetate. Evaporation of the solvent afforded a mixture $(5.7 \mathrm{~g})$ of II and its ester, which was hydrolysed with $2 \mathrm{~N}$ sodium hydroxide solution at $100^{\circ} \mathrm{C}$ for $1 \mathrm{hr}$. The aqueous solution was extracted with ethyl acetate at $\mathrm{pH} 3$. Crude crystals of II obtained by evaporation of the solvent were recrystallized from ethyl acetate-hexane into needles $(4.5 \mathrm{~g}), \mathrm{mp} 102 \sim 103^{\circ} \mathrm{C}$. IR $\vee \mathrm{cm}^{-1}: 1710$, 1590, 1510. NMR (in $\mathrm{CD}_{3} \mathrm{COCD}_{3}$ ) $\tau: 7.37(2 \mathrm{H}, \mathrm{t}$ ), $7.17(2 \mathrm{H}, \mathrm{t}), 6.31(3 \mathrm{H}, \mathrm{s}), 6.20(6 \mathrm{H}, \mathrm{s}), 3.45(2 \mathrm{H}, \mathrm{s})$. MS: $M^{+}, m / e 240$.

5,6,7-Trimethoxy-1-indanone (III). 3-( $3^{\prime}, 4^{\prime}, 5^{\prime}$-Trimethoxyphenyl)-propionic acid (II, $4 \mathrm{~g}$ ) was added to polyphosphoric acid $(50 \mathrm{~g})$ and the mixture was heated at $60^{\circ} \mathrm{C}$ for $1 \mathrm{hr}$ and poured into ice water. The solution was extracted with ether. The solid obtained by evaporation of the solvent was purified through silicic acid column chromatography. Elution with ethyl acetate-benzene (1:99) afforded III $(2.9 \mathrm{~g})$, mp $107 \sim 108^{\circ} \mathrm{C} . \quad$ IR $-\mathrm{cm}^{-1}: 1685,1590 . \quad \mathrm{MMR}=: 7.50$ $(2 \mathrm{H}, \mathrm{t}), 7.00(2 \mathrm{H}, \mathrm{t}), 6.25(3 \mathrm{H}, \mathrm{s}), 6.07(6 \mathrm{H}, \mathrm{s}), 3.15$ (1H, s). Ms: M , m/e 222.

5,6,7-Trimethoxy-2-oximino-1-indanone (IV). 5,6,7Trimethoxy-1-indanone (III, $2.8 \mathrm{~g}$ ) was nitrosated with isoamyl nitrite $(4 \mathrm{ml})$ in the same way as that described by Matsui et al. Crude IV was crystallized into needles $(2.7 \mathrm{~g}), \mathrm{mp} 189 \sim 190^{\circ} \mathrm{C}$. IR $\nu \mathrm{cm}^{-1}$ : $3240,1710,1650,1590$. NMR (in $\mathrm{CD}_{3} \mathrm{COCD}_{3}$ ) $\approx$ : $7.22(2 \mathrm{H}, \mathrm{s}), 6.20(3 \mathrm{H}, \mathrm{s}), 6.02(6 \mathrm{H}, \mathrm{s}), 3.05(1 \mathrm{H}, \mathrm{s})$, -1.31 (1H,s). MS: $\mathrm{M}^{-}$, m/e 251.

2-Carboxy-3,4,5-trimethoxyphenylacetic acid ( $\mathrm{Va}$ ). The Beckmann rearrangement followed by alkali hydrolysis was conducted in the same way as that of Matsui et al. From IV $(0.3 \mathrm{~g})$, Va $(0.26 \mathrm{~g})$ was obtained. 
Mp I51 C. IR $\vee \mathrm{cm}^{-1}: 2600,1720,1685,1590$. MS: $\mathrm{M}, \mathrm{m} / \mathrm{e} 270$.

3-Methyl-6,7,8-trimethoxyisocoumarin (IC). 2-Carboxy-3,4,5-trimethoxyphenylacetic acid ( $\mathrm{Va}, 0.26 \mathrm{~g}$ ) was refluxed in acetic anhydride $(10 \mathrm{ml})$ at $130^{\circ} \mathrm{C}$ for $2 \mathrm{hr}$ and then acetic anhydride was removed in vacuo. The resulting residue was dissolved in ethyl acetate and the ethyl acetate solution was washed with sodium bicarbonate solution, dried with anhyd, sodium sulfate and concentrated to give crude crystals of Ic $(0.25 \mathrm{~g})$, which was recrystallized from ethyl acetatehexane into rods, $\mathrm{mp} 118^{\circ} \mathrm{C}$. IR $\nu \mathrm{cm}^{-1}: 1700,1670$, 1600, 1560. NMR $\tau: 7.80(3 \mathrm{H}, \mathrm{s}), 6.13(3 \mathrm{H}, \mathrm{s}), 6.09$ $(3 \mathrm{H}, \mathrm{s}), 6.05(1 \mathrm{H}, \mathrm{s}), 3.93(1 \mathrm{H}, \mathrm{s}), 3.50(1 \mathrm{H}, \mathrm{s})$. MS: $\mathrm{M}^{+}, m / e 250$. This compound was identical with the methyl ether of A-substance in all respects.

3-Methyl-6,7-dimethoxy-8-hydroxyisocoumarin (Ia). 3Methyl-6,7,8-trimethoxyisocoumarin (Ic, $50 \mathrm{mg}$ ) was heated at $130^{\circ} \mathrm{C}$ for $2 \mathrm{hr}$ in a solution of acetic acid $(0.66 \mathrm{ml})$ and hydriodic acid (d 1.6, $0.02 \mathrm{ml}$ ). The reaction mixture was concentrated in vacuo and diluted with water $(4 \mathrm{ml})$ and the aqueous solution was extracted with ethyl acetate. The organic layer was washed with water, $5 \%$ aqueous sodium thiosulfate and sat. brine, successively. The solvent was removed in vacuo to give crude crystals of la $(39 \mathrm{mg}$ ), which were recrystallized from ethyl acetate-hexane, $\mathrm{mp}$ $193^{\circ} \mathrm{C}$. IR $ข \mathrm{~cm}^{-1}: 1680,1640,1560,1520$. NMR $\therefore 7.70(3 \mathrm{H}, \mathrm{s}), 6.10(3 \mathrm{H}, \mathrm{s}), 6.05(3 \mathrm{H}, \mathrm{s}), 3.75(1 \mathrm{H}$, s), $3.60(1 \mathrm{H}, \mathrm{s}),-1.05(1 \mathrm{H}, \mathrm{s})$. MS: M+, mie 236. This compound was identical with A-substance in all respects.

3-Methylisocoumarin (If) and 3-methyl-6,8-dimethoxyisocoumarin (Id). Homophthalic acid or 2-carboxy-3, 5-dimethoxyphenylacetic acid7 ( $1.5 \mathrm{~g}$ ) was refluxed in acetic anhydride $(15 \mathrm{ml})$ for $2 \mathrm{hr}$ to yield If $(0.57$ $\mathrm{g})$ or Id $(0.91 \mathrm{~g})$. If: $\mathrm{Mp} 72^{\circ} \mathrm{C}$. IR $/ \mathrm{cm}^{-1}: 1740$, $1670,1620,1580$. NMR :: $7.80(3 \mathrm{H}, \mathrm{s}), 3.90(1 \mathrm{H}$, s), $2.73 \sim 2.40(3 \mathrm{H}, \mathrm{m}), 1.91(\mathrm{lH}, \mathrm{d}) . \mathrm{MS}: \mathrm{M}^{+}, \mathrm{m} / \mathrm{e}$ 160. Id: $\mathrm{Mp} 157 \sim 158^{\circ} \mathrm{C}$. IR $\nu \mathrm{cm}^{-1}$ : 1715,1670 , 1605, 1570. NMR :: $7.75(3 \mathrm{H}, \mathrm{s}), 6.08(3 \mathrm{H}, \mathrm{s}), 6.02$ $(3 \mathrm{H}, \mathrm{s}), 3.92(1 \mathrm{H}, \mathrm{s}), 3.70(\mathrm{HH}, \mathrm{d}), 3.60(1 \mathrm{H}, \mathrm{d})$. MS: $\mathrm{M}+, m / e 220$.

3-Methyl-6-methoxy-8-hydroxyisocoumarin (Ie). 3Methyl-6,8-dimethoxyisocoumarin (Id, $0.5 \mathrm{~g}$ ) was hydrolysed with hydriodic acid to give (Ie, $0.45 \mathrm{~g}$ ) in the same condition as in the hydrolysis of Ic. Mp $155^{\circ} \mathrm{C}$. IR $\nu \mathrm{cm}^{-1}: 1695,1655,1580,1530 . \quad$ NMR (in $\left.\mathrm{CD}_{3} \mathrm{COCD}_{3}\right) \tau: 7.78(3 \mathrm{H}, \mathrm{s}), 6.14(3 \mathrm{H}, \mathrm{s}), 3.66$ $(1 \mathrm{H}, \mathrm{s}), 3.62(2 \mathrm{H}, \mathrm{s}),-1.10(1 \mathrm{H}, \mathrm{s})$. MS: $\mathrm{M}^{+}, m / e 206$.

3-Ethoxy-6,8-dimethoxyisocoumarin (VIb). 2-Carboxy3,5-dimethoxyphenylacetic acid $(0.1 \mathrm{~g})$ was dissolved in abs. ethanol (2 $\mathrm{ml}$ ) and a few drop of conc, sulfuric acid was added to it. The solution was refluxed for $30 \mathrm{~min}$ and water $(50 \mathrm{ml})$ was added. The aqueous solution was extracted with ethyl acetate. Evaporation of the solvent afforded the half ester (Vc, 50 $\mathrm{mg}), \mathrm{mp} 111^{\circ} \mathrm{C}$. IR $ข \mathrm{~cm}^{-1}: 1735,1660,1605,1570$. NMR $\tau: 8.72(3 \mathrm{H}, \mathrm{t}), 6.15(3 \mathrm{H}, \mathrm{s}), 6.05(2 \mathrm{H}, \mathrm{s})$, $6.02(3 \mathrm{H}, \mathrm{s}), 5.83(2 \mathrm{H}, \mathrm{q}), 3.52(2 \mathrm{H}, \mathrm{d}) . \mathrm{MS}: \mathrm{M} \div$, $m / e$ 268. This structure was confirmed by the comparison of its IR spectra with that of $\mathrm{Vd}^{7}$ which was obtained by alkali hydrolysis of the dimethyl ester. The half ester ( $\mathrm{Vc}, 50 \mathrm{mg}$ ) was refluxed in acetic anhydride for $2 \mathrm{hr}$. After acetic anhydride was removed in vacuo, water was added and the aqueous solution was extracted with ethyl acetate. Evaporation of the solvent afforded VIb (48 mg), mp $114^{\circ} \mathrm{C}$. IR $\nu \mathrm{cm}^{-1}: 1725,1645,1600,1560$. NMR :: $8.75(3 \mathrm{H}, \mathrm{t}), 6.17(3 \mathrm{H}, \mathrm{s}), 6.04(3 \mathrm{H}, \mathrm{s}), 5.85(2 \mathrm{H}, \mathrm{q})$, $3.55(2 \mathrm{H}, \mathrm{s})$. MS: MI- ${ }^{-}, \mathrm{e} / 250$.

3-Ethoxy-6,7,8-trimethoxyisocoumarin (VIa). 2-Carboxy-3,4,5-trimethoxyphenylacetic acid (Va, $1 \mathrm{~g}$ ) was converted to the half ester (Vb), which was treated with acetic anhydride to give VIa $(0.3 \mathrm{~g})$. Vb: Mp $91^{\circ} \mathrm{C}$. IR $\vee \mathrm{cm}^{-1}: 1735,1675,1590,1570$. NMR : $8.72(3 \mathrm{H}, \mathrm{t}), 6.12(3 \mathrm{H}, \mathrm{s}), 6.07(3 \mathrm{H}, \mathrm{s}), 6.05(2 \mathrm{H}, \mathrm{s})$, $5.95(3 \mathrm{H}, \mathrm{s}), 5.85(2 \mathrm{H}, \mathrm{q})$. MS: $\mathrm{M}^{+}$, m/e 298. Vla: $\mathrm{Mp} 82^{\circ} \mathrm{C}$. IR $\nu \mathrm{cm}^{-1}: 1730,1650,1590,1545$. NMR (in $\left.\mathrm{CD}_{3} \mathrm{COCD}_{3}\right) \tau: 8.61(3 \mathrm{H}, \mathrm{t}), 6.21(3 \mathrm{H}, \mathrm{s}), 6.11$ $(3 \mathrm{H}, \mathrm{s}), 6.05(3 \mathrm{H}, \mathrm{s}), 5.90(2 \mathrm{H}, \mathrm{q}), 4.32(1 \mathrm{H}, \mathrm{s})$. MS: $\mathrm{M}^{+}, m_{j} / e 280$.

Preparation of 1-hydroxyisoquinoline derivatives. 3Methylisocoumarin derivatives (Ia, c, d, i, f) was dissolved in $280^{\circ}$ ammonia $(50 \mathrm{ml})$ and the solution was heated in a seeled tube at $100^{\circ} \mathrm{C}$ for $5 \mathrm{hr}$. The cooled solution was extracted with ethyl acetate. Evaporation of the solvent afforded 3-methyl-1hydroxyisoquinoline derivatives (VIIa, c, d, e, f) in $900 \%$ yield. VIla: Mp $225^{\circ} \mathrm{C}$. IR \& $\mathrm{cm}^{-1}: 1660$, 1620,1530 . NMR :: $7.68(3 \mathrm{H}, \mathrm{s}), 6.08(6 \mathrm{H}, \mathrm{s}), 3.78$ $(1 \mathrm{H}, \mathrm{s}), 3.65(1 \mathrm{H}, \mathrm{s}),-1.24(1 \mathrm{H}, \mathrm{s}),-2.51(1 \mathrm{H}, \mathrm{s})$. MS: $\mathrm{M}^{+}, m / e$ 235. VIIc: Mp $230^{\circ} \mathrm{C}$. IR $\vee \mathrm{cm}^{-1}$; $1670,1635,1560,1520$. NMR $\tau: 7.68(3 \mathrm{H}, \mathrm{s}), 6.08$ $(9 \mathrm{H}, \mathrm{s}), 3.80(1 \mathrm{H}, \mathrm{s}), 3.65(1 \mathrm{H}, \mathrm{s}),-1.50(1 \mathrm{H}, \mathrm{s})$. 
MS: M,$m / e$ 249. VIId: Mp $229^{\circ} \mathrm{C}$. IR \& $\mathrm{cm}^{-1}$ : $1640,1610,1560$. NMR $=: 7.70(3 \mathrm{H}, \mathrm{s}), 6.18(3 \mathrm{H}$, s), $6.10(3 \mathrm{H}, \mathrm{s}), 3.92(1 \mathrm{H}, \mathrm{s}), 3.68(2 \mathrm{H}, \mathrm{s}),-1.10$ (IH, s). MS: $\mathrm{M} \div$. m/e 219. VIIe: Mp $228^{\circ} \mathrm{C}$. IR $\nu$ $\mathrm{cm}^{-1}: 1650,1620,1550$. NMR: (in $\mathrm{C}_{5} \mathrm{D}_{5} \mathrm{~N}$ ) $\tau: 7.77$ $(3 \mathrm{H}, \mathrm{s}), 6.25(3 \mathrm{H}, \mathrm{s}), 3.77(1 \mathrm{H}, \mathrm{s}), 3.47(1 \mathrm{H}, \mathrm{d}), 3.28$ $(1 \mathrm{H}, \mathrm{d}),-2.70(1 \mathrm{H}, \mathrm{s}),-4.00(1 \mathrm{H}, \mathrm{s})$. MS: $\mathrm{M}^{+}$, $m / e$ 205. VIIf: $\mathrm{Mp} 210^{\circ} \mathrm{C}$. IR $\nu \mathrm{cm}^{-1}: 1660,1640$, 1600, 1550. NMR :: $7.61(3 \mathrm{H}, \mathrm{s}), 3.72(1 \mathrm{H}, \mathrm{s}), 2.67$ $(1 \mathrm{H}, \mathrm{s}), 2.57(1 \mathrm{H}, \mathrm{s}), 2.47(1 \mathrm{H}, \mathrm{d}), 1.67(1 \mathrm{H}, \mathrm{d})$, -1.73 (1H, s). MS: M广, m/e 159.

Acknowledgement. The authors wish to express their thanks to Mr. Aizawa and his colleagues of Laboratory of Instrumental Analysis for determination of various spectra.

\section{REFERENCES}

1) S. Tamura, N. Takahashi, S. Miyamoto, R. Mori, S. Suzuki and J. Nagatsu, Agr. Biol. Chem., 27, 576 (1963).

2) N. Takahashi, A. Suzuki, Y. Kimura, S. Miyamoto, S. Tamura, T. Mitsui and J. Fukami, ibid, 32, 1115 (1968).

3) J. Lin, S. Yoshida and N. Takahashi, ibid., 35, 363 (1971); M. A. W. Eaton and D. W. Hutchinson, Tetrahedron Letters, 1971, 1337.

4) L. A. Mitscher, W. W. Andres and W. Magrae, Experientia, 20, 258 (1964).

5) J. Koo, J. Am. Chem. Soc., 73, 1889 (1953).

6) M. Matsui, K. Mori and S. Arasaki, Agr. Biol. Chem., 28, 896 (1964).

7) H. Nogami, Yakugakuzasshi, 61, 56 (1941). 